\title{
Structural Stability of Clean and Passivated Nanodiamonds having Ledge, Step, or Corner Features
}

\author{
Denis Tarasov ${ }^{1}$, Ekaterina Izotova² ${ }^{2}$ Diana Alisheva², Natalia Akberova², and Robert A. Freitas, Jr. 3,* \\ ${ }^{1}$ Kazan Branch of Joint Supercomputer Center, Russian Academy of Sciences, Kazan, 420111, Russia \\ 2 Kazan Federal University, Department of Biochemistry, Kazan, Tatarstan, 420008, Russia \\ ${ }^{3}$ Institute for Molecular Manufacturing, Palo Alto, CA 94301, USA
}

\begin{abstract}
The use of precisely applied mechanical forces to induce site-specific chemical transformations is called positional mechanosynthesis, and diamond is an important early target for achieving mechanosynthesis experimentally. The next major experimental milestone may be the mechanosynthetic fabrication of atomically precise 3D structures, creating readily accessible diamond-based nanomechanical components engineered to form desired architectures possessing superlative mechanical strength, stiffness, and strength-to-weight ratio. To help motivate this future experimental work, the present paper addresses the basic stability of nanoscale diamond structures with clean or hydrogenated surfaces that possess certain simple features including ledges, steps, and corners. Computational studies using Density Functional Theory (DFT) with the Car-Parrinello Molecular Dynamics (CPMD) code, consuming 2,284,108.97 CPU-hours of runtime on the IBM Blue Gene/P supercomputer (23 TFlops), confirm that fully hydrogenated nanodiamonds 1-2 $\mathrm{nm}$ in size possessing ledges with various combinations of convex or concave edgelines where any two of the three principal diamond faces meet will maintain stable $\mathrm{sp}^{3}$ hybridization.
\end{abstract}

Keywords: Carbon, Corner, Cuboid, Diamond, DFT, DMS, Ledge, Mechanosynthesis, Nanocarbon, Nanodiamond, Nanopart, Nanotechnology, Octahedron, Reconstruction, Stability, Step.

\section{INTRODUCTION}

The present work extends the analysis of the stability of octahedral and cuboid nanoscale diamond structures first reported in prior work by Tarasov et al. ${ }^{1}$

The use of precisely applied mechanical forces to induce site-specific chemical transformations using positionallycontrolled highly reactive tools in nonreactive environments such as UHV is called positional diamond mechanosynthesis (DMS). ${ }^{2,3}$ Positional mechanosynthesis has been demonstrated experimentally for $\mathrm{Si}, \mathrm{Ge}, \mathrm{Sn}$ and $\mathrm{Pb},{ }^{4-6}$ and $\mathrm{C}$ mechanosynthesis is being efforted. ${ }^{7}$ The next major experimental milestone may be the mechanosynthetic fabrication of atomically precise 3D structures, creating readily accessible diamond-based nanomechanical components engineered to form desired architectures possessing superlative mechanical strength, stiffness, and strength-to-weight ratio. These nanoscale components may range from relatively simple diamond cubes, rods or rings to more sophisticated "nanoparts"

*Author to whom correspondence should be addressed such as fullerene bearings, ${ }^{8-10}$ gears ${ }^{11-13}$ and motors, ${ }^{14}$ composite fullerene/diamond structures, ${ }^{15}$ and more complex devices ${ }^{16}$ such as diamondoid gears, ${ }^{17}$ pumps, ${ }^{17}$ and conveyors. ${ }^{18}$

To help motivate this future experimental work, the present paper addresses the basic stability of nanoscale diamond structures with clean or hydrogenated surfaces that possess certain simple features including ledges, steps, and corners.

\section{COMPUTATIONAL METHODS}

The simplest nanoparts will consist entirely of flat plane surfaces that intersect at an edgeline, or at a corner point in the case of three or more intersecting planes. Previous work $^{1}$ has analyzed the facial surface stability of the three principal crystal planes in diamond: $\mathrm{C}(100), \mathrm{C}(110)$ and $\mathrm{C}(111)$. The present work considers the issue of structural stability at the intersections of these planes along both convex or "outside" edgelines and concave or "inside" edgelines, along with the stability of various ledge and step structures. 
Table I. Nanodiamond structures with ledge, step, or corner features.

\begin{tabular}{|c|c|c|c|c|c|}
\hline \multicolumn{3}{|c|}{ Clean (Dehydrogenated) Diamond } & \multicolumn{3}{|c|}{ Fully Passivated (Hydrogenated) Diamond } \\
\hline Structure Name & Total \# of Atoms & Chemical Formula & Structure Name & Total \# of Atoms & Chemical Formula \\
\hline C100Cube $15 \times 15$ & 1098 & $\mathrm{C}_{1098}$ & C100Cube $15 \times 15-\mathrm{H}$ & 1474 & $\mathrm{C}_{1098} \mathrm{H}_{376}$ \\
\hline Ledge100-110D & 1032 & $\mathrm{C}_{1032}$ & Ledge100-110D-H & 1434 & $\mathrm{C}_{1032} \mathrm{H}_{402}$ \\
\hline Ledge100-110C & 1060 & $\mathrm{C}_{1060}$ & Ledge100-110C-H & 1466 & $\mathrm{C}_{1060} \mathrm{H}_{406}$ \\
\hline Ledge100-110B & 1128 & $\mathrm{C}_{1128}$ & Ledge100-110B-H & 1542 & $\mathrm{C}_{1128} \mathrm{H}_{414}$ \\
\hline Ledge100-110A & 1156 & $\mathrm{C}_{1156}$ & Ledge100-110A-H & 1574 & $\mathrm{C}_{1156} \mathrm{H}_{418}$ \\
\hline CutCube15x15 & 1266 & $\mathrm{C}_{1266}$ & CutCube15x15-H & 1676 & $\mathrm{C}_{1266} \mathrm{H}_{410}$ \\
\hline CutCube15x15A & 1224 & $\mathrm{C}_{1224}$ & CutCube15x15A-H & 1628 & $\mathrm{C}_{1224} \mathrm{H}_{404}$ \\
\hline Step111AA & 651 & $\mathrm{C}_{651}$ & Step111AA-H & 933 & $\mathrm{C}_{651} \mathrm{H}_{282}$ \\
\hline Step111A & 651 & $\mathrm{C}_{651}$ & & & \\
\hline Ledge100-111A & 1144 & $\mathrm{C}_{1144}$ & Ledge100-111A-H & 1546 & $\mathrm{C}_{1144} \mathrm{H}_{402}$ \\
\hline Ledge100-111B & 1102 & $\mathrm{C}_{1102}$ & Ledge100-111B-H & 1492 & $\mathrm{C}_{1102} \mathrm{H}_{390}$ \\
\hline Ledge100-111D & 1080 & $\mathrm{C}_{1080}$ & Ledge100-111D-H & 1488 & $\mathrm{C}_{1080} \mathrm{H}_{408}$ \\
\hline Ledge100-111C & 1108 & $\mathrm{C}_{1108}$ & Ledge100-111C-H & 1520 & $\mathrm{C}_{1108} \mathrm{H}_{412}$ \\
\hline Ledge100-111E & 1044 & $\mathrm{C}_{1044}$ & Ledge100-111E-H & 1448 & $\mathrm{C}_{1044} \mathrm{H}_{404}$ \\
\hline Ledge110-110 & 992 & $\mathrm{C}_{992}$ & Ledge110-110-H & 1392 & $\mathrm{C}_{992} \mathrm{H}_{400}$ \\
\hline Ledge110-111A & 1084 & $\mathrm{C}_{1084}$ & Ledge110-111-H & 1496 & $\mathrm{C}_{1084} \mathrm{H}_{412}$ \\
\hline Ledge110-111B & 845 & $\mathrm{C}_{845}$ & & & \\
\hline Octa $16 \times 16$ & 969 & $\mathrm{C}_{969}$ & Octa16x16-H & 1293 & $\mathrm{C}_{969} \mathrm{H}_{324}$ \\
\hline Step111B & 620 & $\mathrm{C}_{620}$ & Step111B-H & 890 & $\mathrm{C}_{620} \mathrm{H}_{270}$ \\
\hline Ledge111-111 & 914 & $\mathrm{C}_{914}$ & Ledge111-111-H & 1266 & $\mathrm{C}_{914} \mathrm{H}_{352}$ \\
\hline
\end{tabular}

All non-step structures in the present work are 9141676 atoms in size and most were carved from an energy-minimized Cube $15 \times 15$ template (a representative $(\sim 2 \mathrm{~nm})^{3}$ cuboid nanodiamond possessing only $\mathrm{C}(100)$ and $\mathrm{C}(110)$ faces, described elsewhere ${ }^{1}$ ) by adding one or two cutfaces to the diamond cuboid. For a representative selection of clean (dehydrogenated) and fully passivated (hydrogenated) ledge and step structures (Table I), we have computed minimum energy geometries and examined the results for changes in bond length, structural rearrangements, graphitization, or other evidence of lattice instability.

There are 6 unique edgeline types that can be formed from an intersection of the three principal diamond planes, with two variants of each edgeline type (convex and concave):

(1) C(100)-C(100). Convex: A single diagonal C(100) cutface on Cube15x15 yields two C(100)-C(100) edgelines, one along the front edge (front vertical face dimer rows running top/bottom) and another along the back edge (back vertical face dimer rows running left/right) of the cutface in C100Cube15x15 (Fig. 1a). Concave: No examples tested; this edgeline should be rare.

(2) C(100)-C(110). Convex: There are 8 edgelines of this type on every cuboid nanopart. ${ }^{1}$ Concave: A vertical cutface and a horizontal cutface on Cube $15 \times 15$ produces a right-angle ledge structure having a C(100)-C(110) concave edgeline with four permutations: (a) left/rightrunning dimer rows on horizontal cutface in "high" position (Ledge100-110D, Fig. 2a), (b) front/back-running dimer rows on horizontal cutface in "high" position (Ledge100-110C, Fig. 2c), (c) left/right dimer-running rows on horizontal cutface in "low" position (Ledge100110B, Fig. 2e), and (d) front/back-running dimer rows on horizontal cutface in "low" position (Ledge100-110A, Fig. 2g).

(3) C(100)-C(111). Convex: A single diagonal C(111) cutface on Cube $15 \times 15$ yields a $\mathrm{C}(100)-\mathrm{C}(111)$ edgeline running front/back at the bottom of the cutface, on CutCube15x15 (Fig. 3a) with right vertical face dimer rows running front/back and on CutCube15x15A (Fig. 3c) with right vertical face dimer rows running
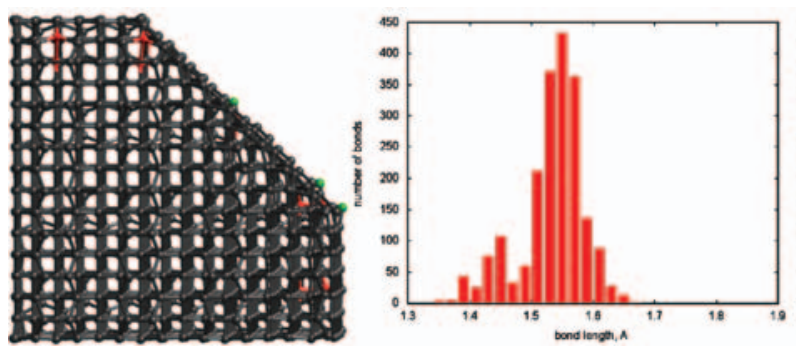

(A)

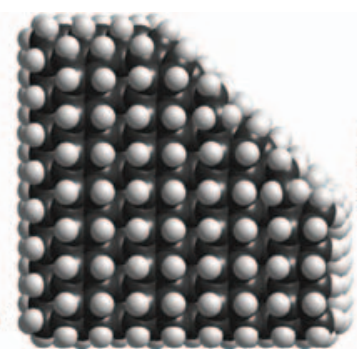

(B)

Fig. 1. Convex $\mathrm{C}(100)-\mathrm{C}(100)$ edgelines: (a) clean and (b) hydrogenated $\mathrm{C} 100 \mathrm{Cube} 15 \times 15$ (C=black, $\mathrm{H}=$ white). $\mathrm{CC}$ bondlengths $\geq 1.70 \AA$ in red; marked atoms in green (see text); bondlength histograms to right of each structure. 


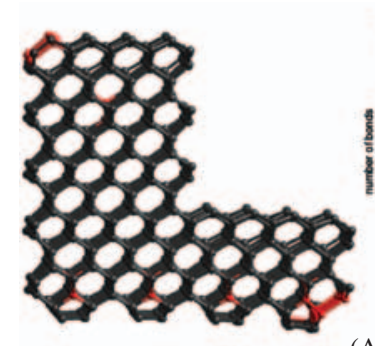

(A)

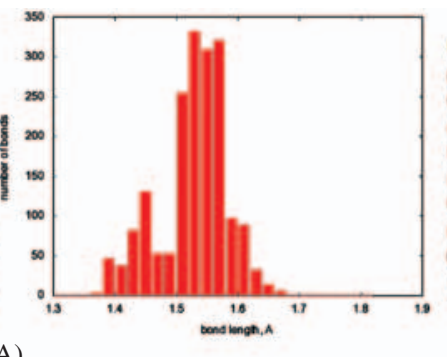

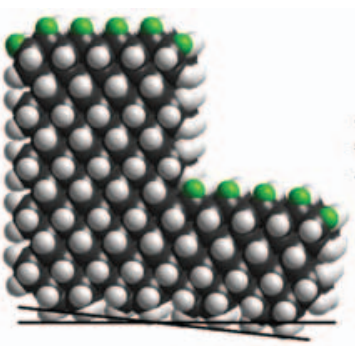

(B)
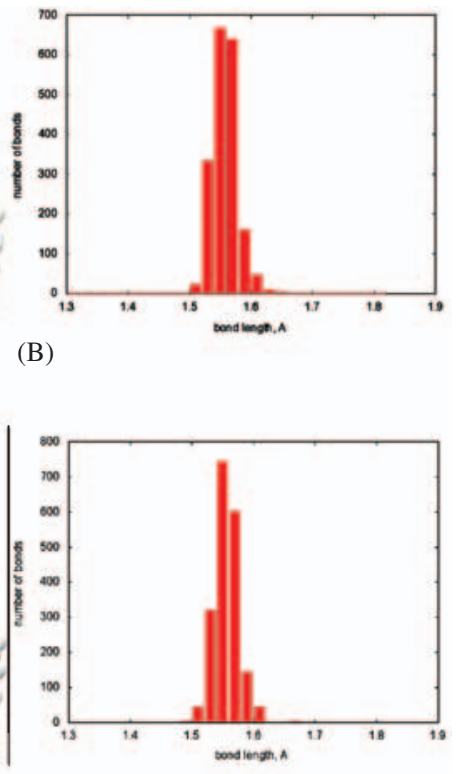

(D)

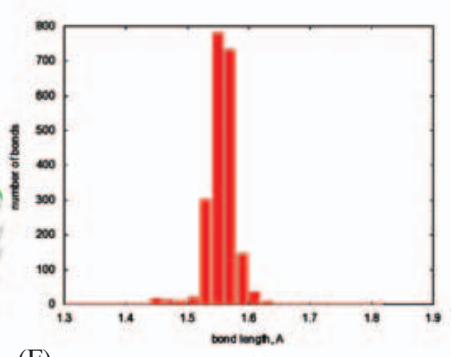

(n)

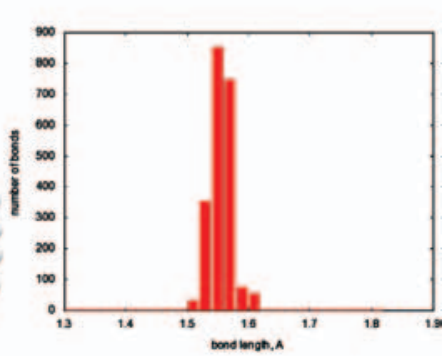

(H)

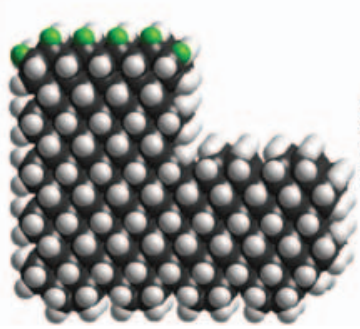

Fig. 2. Concave C(100)-C(110) edgelines: (a) clean and (b) hydrogenated Ledge100-110D; (c) clean and (d) hydrogenated Ledge100-110C; (e) clean and (f) hydrogenated Ledge100-110B; and (g) clean and (h) hydrogenated Ledge100-110A (C=black, H=white). CC bondlengths $\geq 1.70 \AA \AA$ in red; $\mathrm{H}$ atoms (green) are raised $0.1-0.2 \AA$ above the lattice plane; bondlength histograms to right of each structure.

top/bottom. Step111AA (Fig. 4a) also provides a convex $\mathrm{C}(100)-\mathrm{C}(111)$ edgeline along the top edge of the step. Concave: An off-vertical cutface and a horizontal cutface on Cube15x15 produces a $\mathrm{C}(100)-\mathrm{C}(111)$ concave edgeline with (a) an obtuse angle ledge structure having dimer rows running left/right (Ledge100-111A, Fig. 5a) or front/back (Ledge100-111B, Fig. 5c) on the horizontal cutface, or (b) an acute angle ledge structure having dimer rows running left/right (Ledge100-111D, Fig. 6a) in "high" position or running front/back in either "high" position (Ledge100-111C, Fig. 6c) or "low" position (Ledge100-111E, Fig. 6e), on the horizontal cutface.
Step111AA (Fig. 4a) also provides a concave C(100)$\mathrm{C}(111)$ edgeline along the bottom edge of the step.

(4) $\mathbf{C ( 1 1 0 ) - C ( 1 1 0 ) . ~ C o n v e x : ~ T h e r e ~ a r e ~} 4$ edgelines of this type on every cuboid nanopart. ${ }^{1}$ Concave: A vertical cutface and a horizontal cutface on Cube $15 \times 15$ produces a right-angle ledge structure having a $\mathrm{C}(110)-\mathrm{C}(110)$ concave edgeline (Ledge110-110, Fig. 7a).

(5) C(110)-C(111). Convex: A single diagonal C(111) cutface on Cube15x15 yields a C(110)-C(111) edgeline running front/back at the top of the cutface on CutCube15x15 (Fig. 3a) and CutCube15x15A (Fig. 3c). Concave: A diagonally-positioned vertical cutface and a 

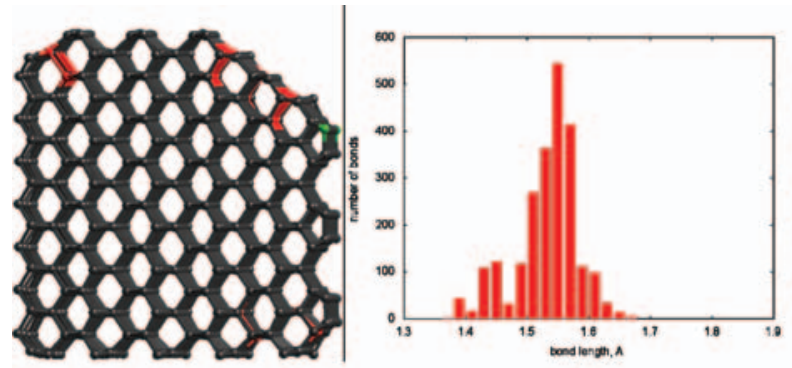

(A)
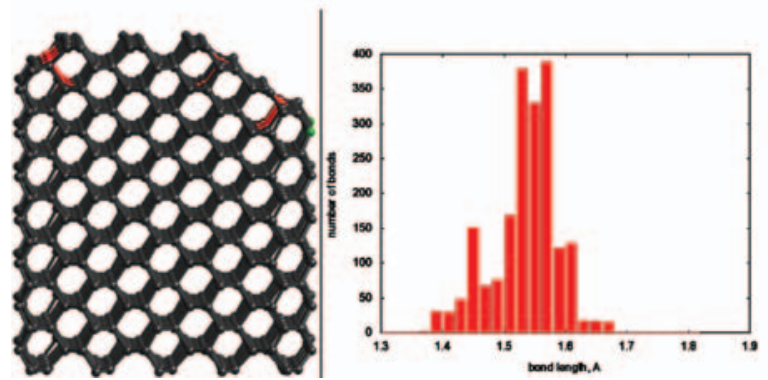

(C)
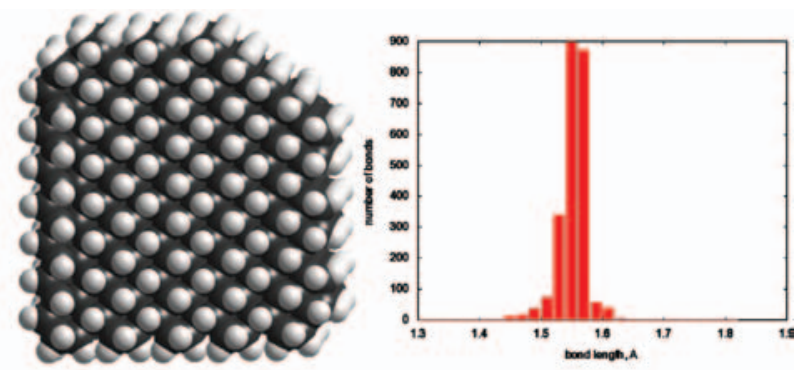

(B)
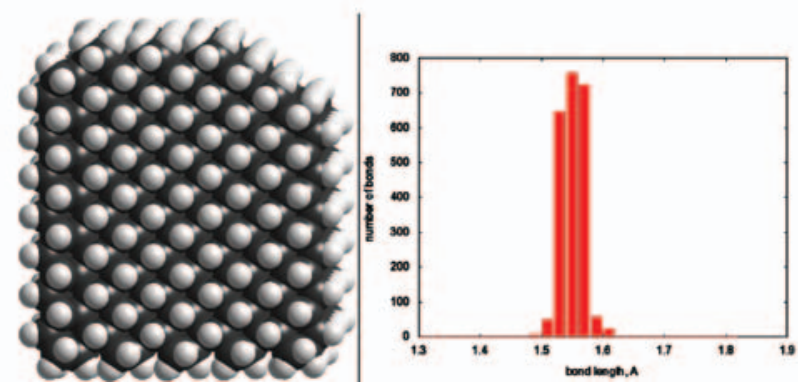

(D)

Fig. 3. Convex $\mathrm{C}(100)-\mathrm{C}(111)$ edgelines: (a) clean and (b) hydrogenated CutCube15x15; (c) clean and (d) hydrogenated CutCube 15x15A (C = black, $\mathrm{H}=$ white). CC bondlengths $\geq 1.70 \AA \AA$ in red; marked atoms in green (see text); bondlength histograms to right of each structure.

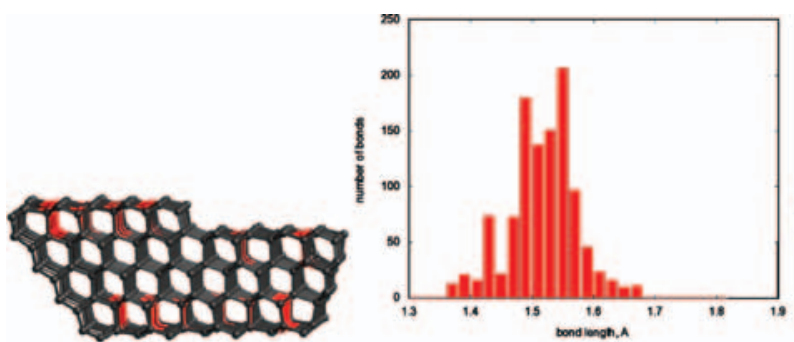

(A)

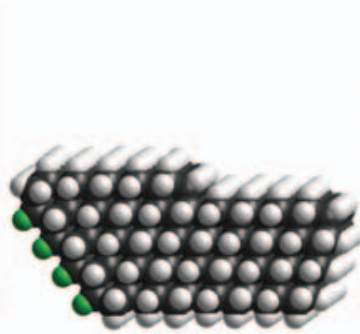

(B)

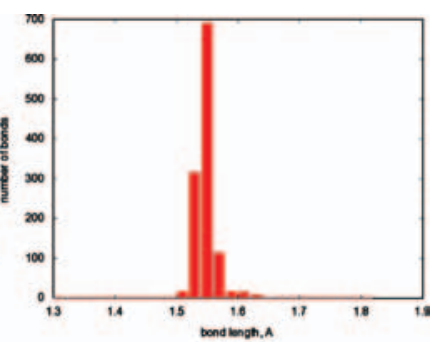

B)

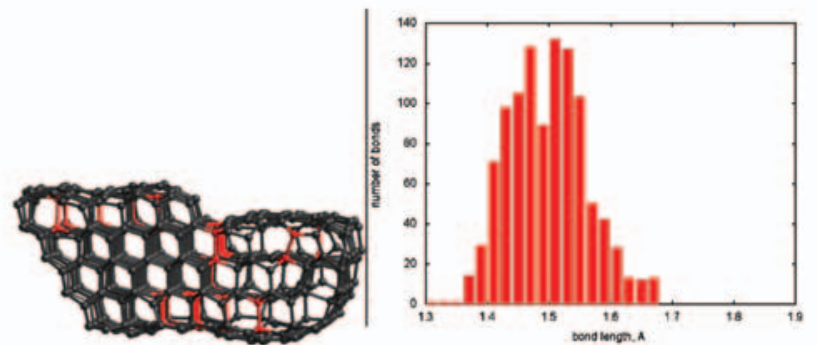

(C)

Fig. 4. Convex and concave C(100)-C(111) edgelines: (a) clean and (b) hydrogenated Step111AA with initial C(100) dimerization, showing convex (top of step) and concave (bottom of step) C(100)-C(111) edgelines; (c) clean Step111A with no initial C(100) dimerization $(\mathrm{C}=$ black, $\mathrm{H}=$ white). CC bondlengths $\geq 1.70 \AA$ in red; $\mathrm{H}$ atoms (green) are raised $0.1-0.2 \AA$ above the lattice plane; bondlength histograms to right of each structure.

horizontal cutface on Cube $15 \times 15$ produces a right-angle ledge structure having a $\mathrm{C}(110)-\mathrm{C}(111)$ concave edgeline (Ledge110-111, Fig. 8a).

(6) C(111)-C(111). Convex: All 12 edgelines of a octahedron nanopart ${ }^{1}$ are of this type, e.g., Octa16x16 (Fig. 9a). Step111B (Fig. 10a) also provides a convex C(111)$\mathrm{C}(111)$ edgeline along the top edge of the step. Concave: An off-vertical cutface and an off-horizontal cutface on Cube15x15 produces a $\mathrm{C}(111)-\mathrm{C}(111)$ concave edgeline with an obtuse angle ledge structure (Ledge111-111, Fig. 11a). Step111B (Fig. 10a) also provides a concave $\mathrm{C}(111)-\mathrm{C}(111)$ edgeline along the bottom edge of the step.

There are 10 unique corner types that can be formed from an intersection of 3 planes (e.g., CutCube15x15, Fig. 3a) and 15 unique corner types that can be formed from an intersection of 4 planes (e.g., Octa16x16, Fig. 9a), with each plane consisting of any one of the three principal 


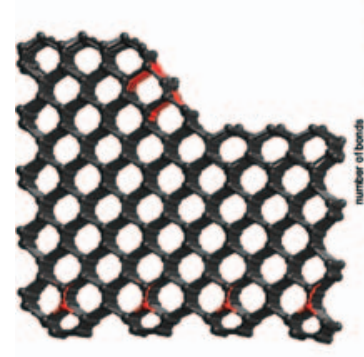

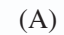
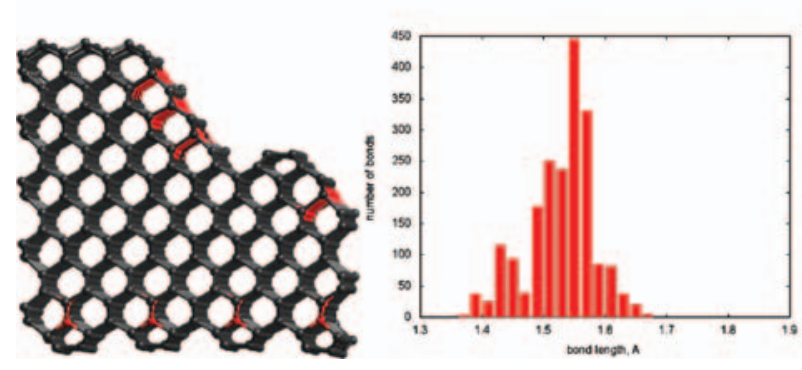

(C)

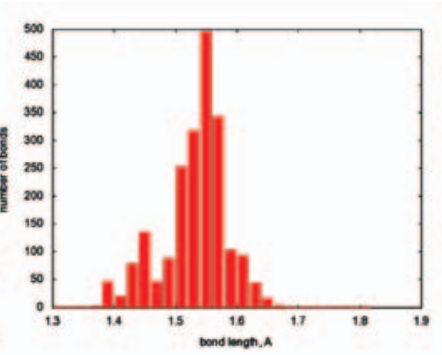

A)
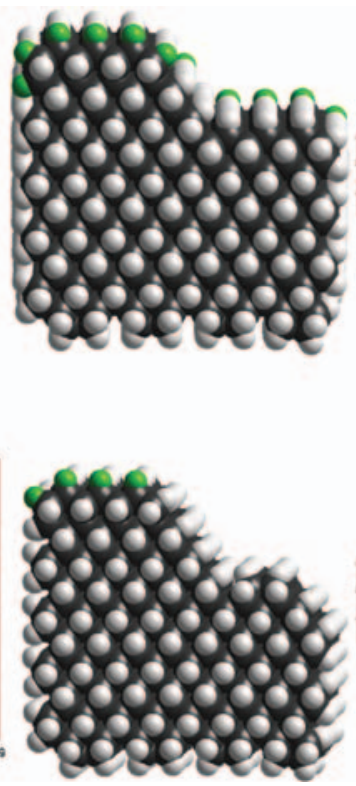

(B)

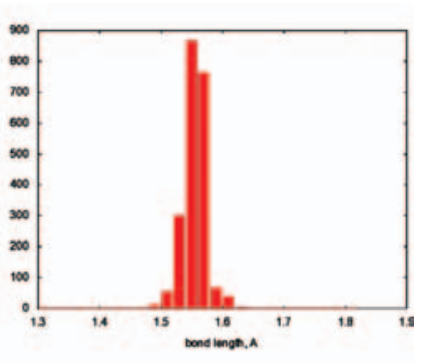

(B)

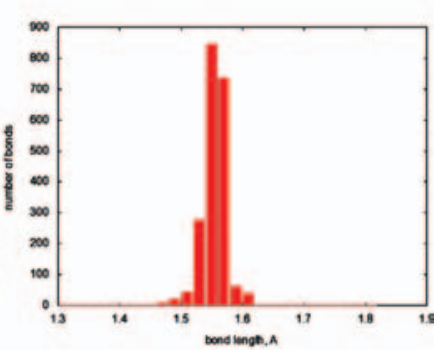

(D)

Fig. 5. Concave obtuse-angle C(100)-C(111) edgelines: (a) clean and (b) hydrogenated Ledge100-111A; (c) clean and (d) hydrogenated Ledge100$111 \mathrm{~B}(\mathrm{C}=$ black, $\mathrm{H}=$ white). $\mathrm{CC}$ bondlengths $\geq 1.70 \AA$ in red; $\mathrm{H}$ atoms (green) are raised $0.1-0.2 \AA$ above the lattice plane; bondlength histograms to right of each structure.
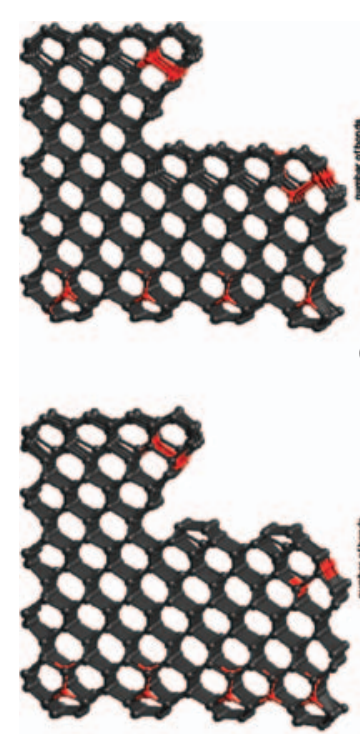

(A)

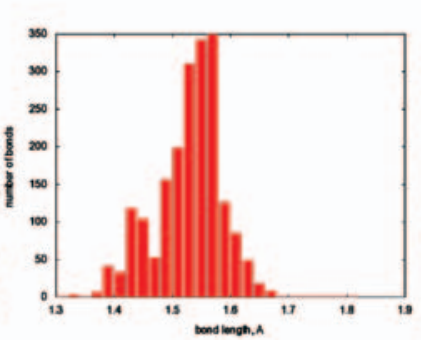

(C)
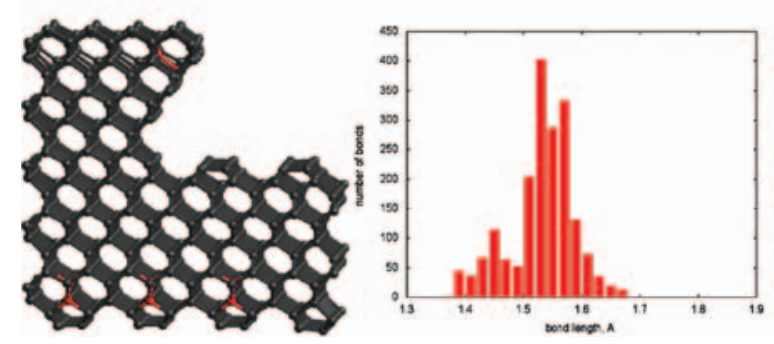

(E)

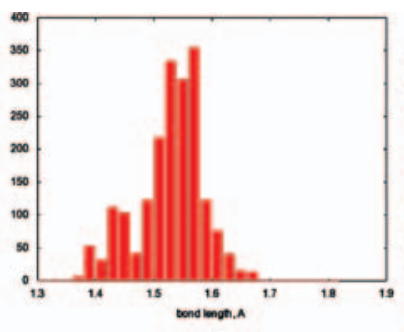

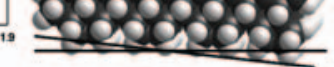
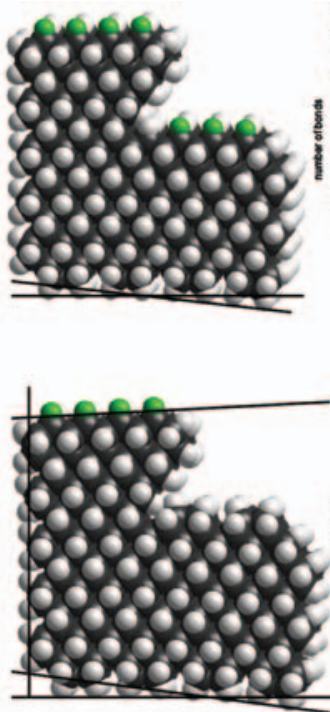

(B)
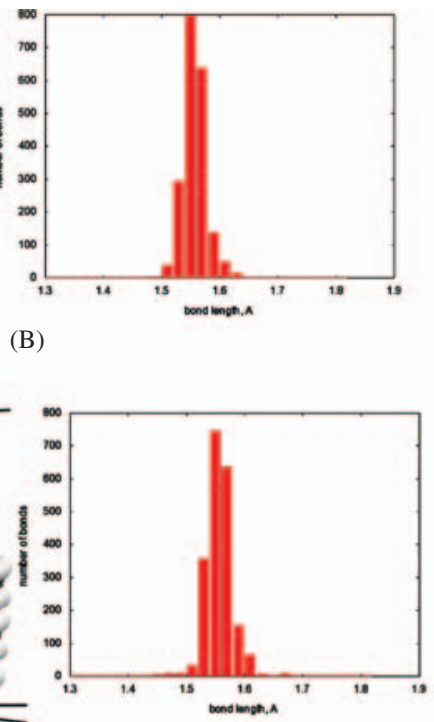

(D)
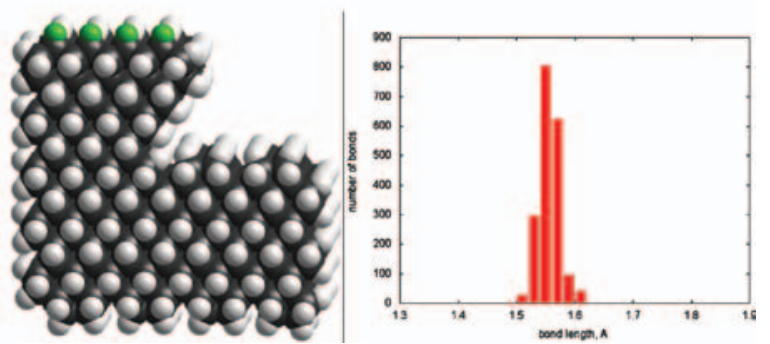

(F)

Fig. 6. Concave acute-angle $\mathrm{C}(100)-\mathrm{C}(111)$ edgelines: (a) clean and (b) hydrogenated Ledge100-111D; (c) clean and (d) hydrogenated Ledge100$111 \mathrm{C}$; and (e) clean and (f) hydrogenated Ledge 100-111E ( $\mathrm{C}=$ black, $\mathrm{H}=$ white). $\mathrm{CC}$ bondlengths $\geq 1.70 \AA$ in red; $\mathrm{H}$ atoms (green) are raised $0.1-0.2 \AA$ above the lattice plane; bondlength histograms to right of each structure. 

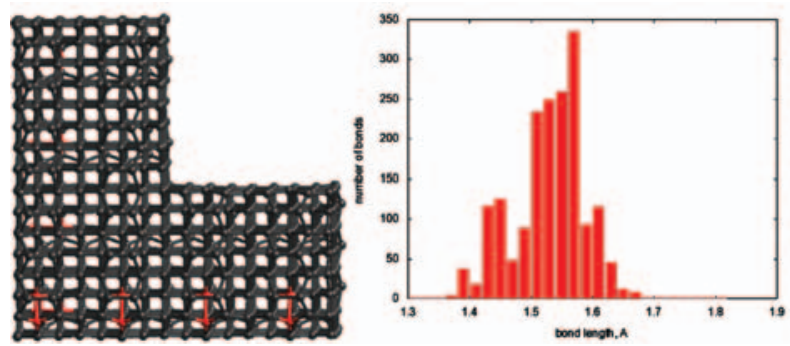

(A)
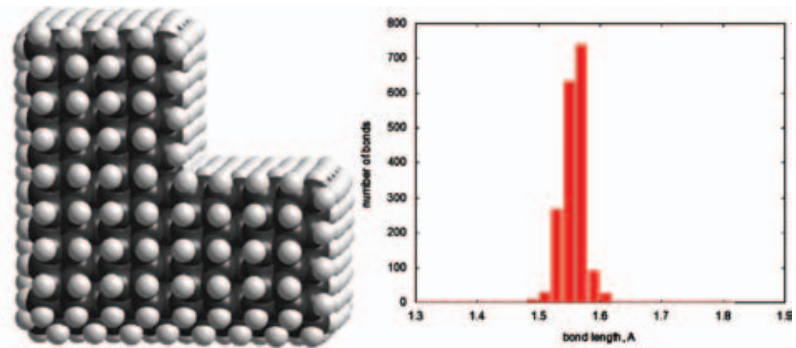

(B)

Fig. 7. Concave $\mathrm{C}(110)-\mathrm{C}(110)$ edgelines: (a) clean and (b) hydrogenated Ledge110-110 (C=black, $\mathrm{H}=$ white). $\mathrm{CC}$ bondlengths $\geq 1.70 \AA$ in red; bondlength histograms to right of each structure.
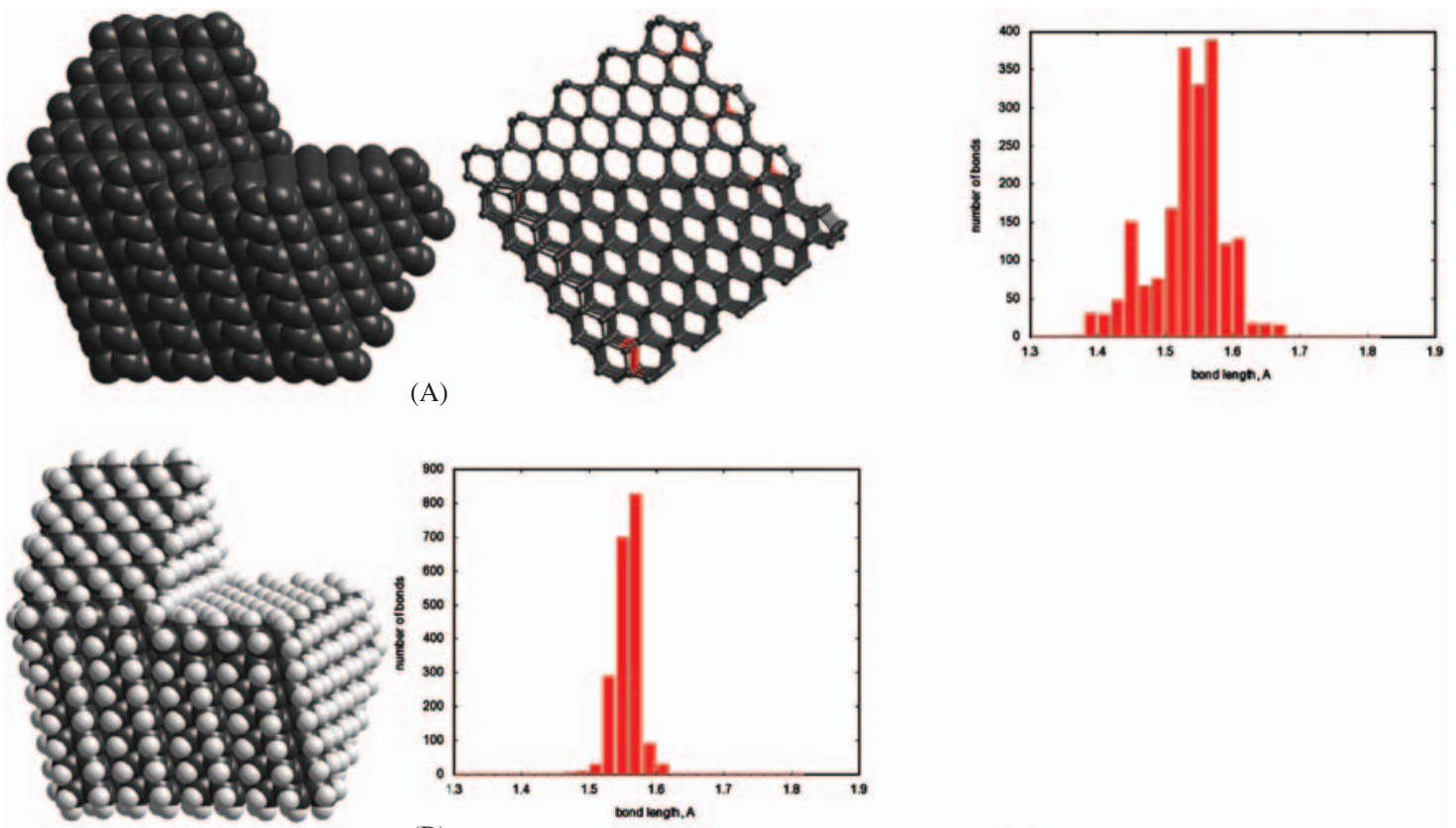

(B)
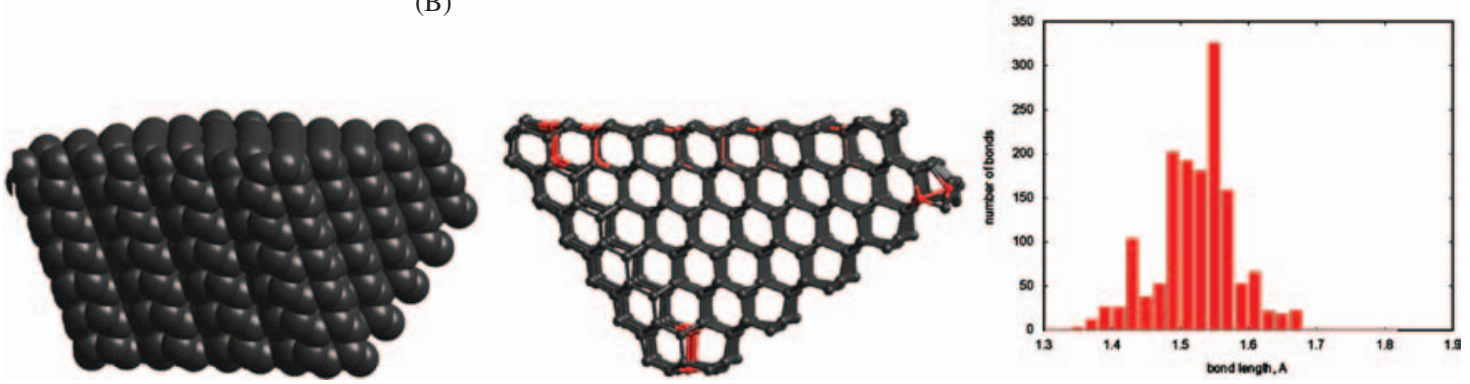

(C)

Fig. 8. Concave $\mathrm{C}(110)-\mathrm{C}(111)$ edgelines: (a) clean and (b) hydrogenated Ledge110-111A ( $\mathrm{C}=$ black, $\mathrm{H}=$ white); (c) same as (a), but with the top section sheared off (Ledge110-111B). CC bondlengths $\geq 1.70 \AA$ in red; bondlength histograms to right of each structure.

diamond planes, plus convex and concave variants of each corner type. Except for the exact vertex point, each such corner type consists of pairwise surface edgelines in various combinations that have already been described above. Similar considerations apply to nanopart surface features such as polygonal holes, slots, notches or troughs having walls consisting of one or more of the three principal diamond planes.
All studies were conducted using DFT consuming $\sim 2,284,108.97$ CPU-hours of runtime on the IBM Blue Gene/P supercomputer (23 TFlops) installed at Moscow State University. Most calculations were performed at low-spin multiplicities using the Car-Parrinello Molecular Dynamics (CPMD) code, ${ }^{19}$ a parallelized planewave/pseudopotential implementation of DFT particularly designed for ab-initio molecular dynamics. Computations 

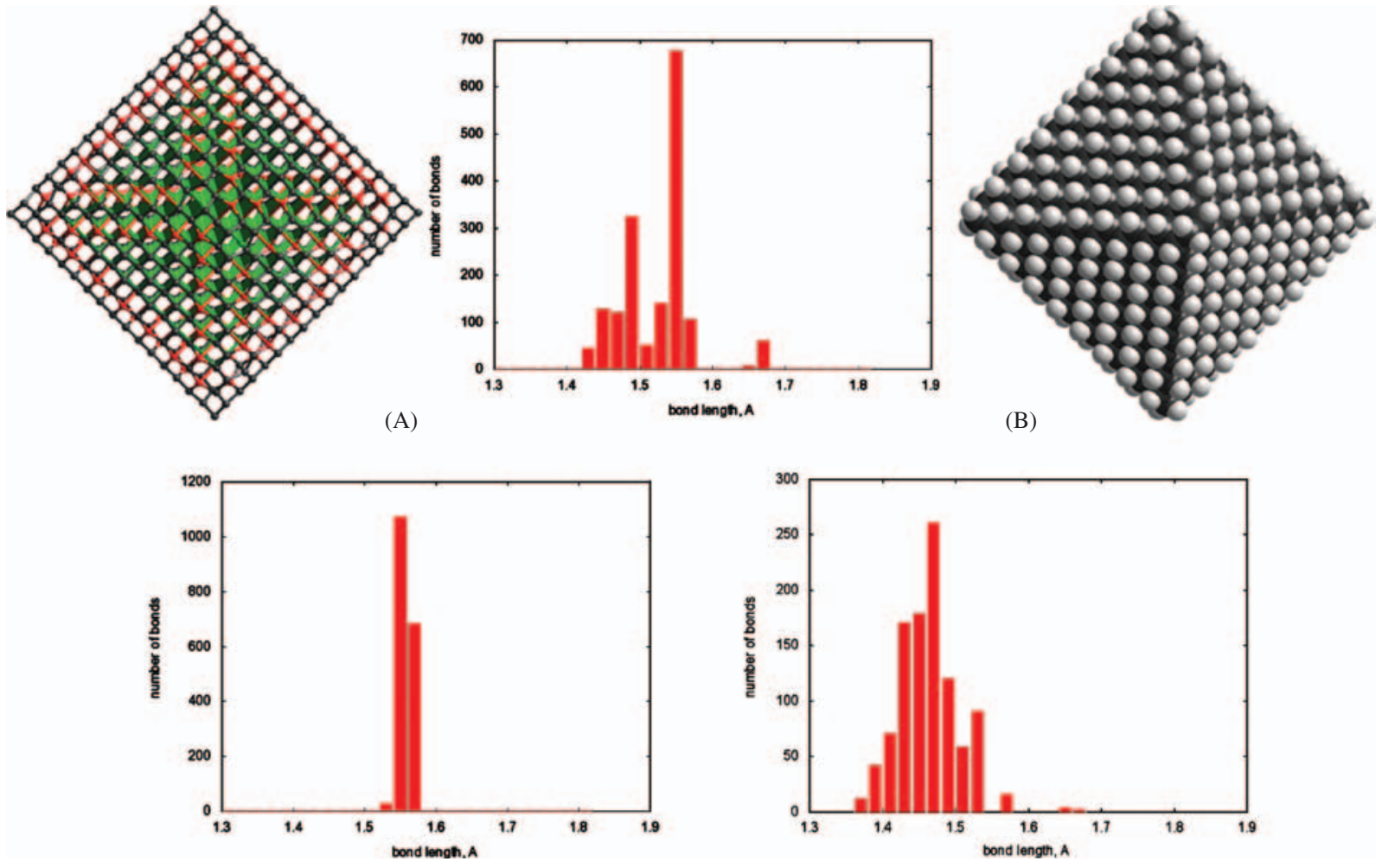

(B)

(C)

Fig. 9. Convex $\mathrm{C}(111)-\mathrm{C}(111)$ edgelines: (a) clean and (b) hydrogenated octahedral nanodiamond Octa16x16 ( $\mathrm{C}=$ black, $\mathrm{H}=$ white). $\mathrm{CC}$ bondlengths $\geq 1.70 \AA$ in red; diamond core atoms in green; bondlength histograms to right of each structure. For comparison to (a), (c) shows bond histogram for clean Octa14x14 from earlier work.

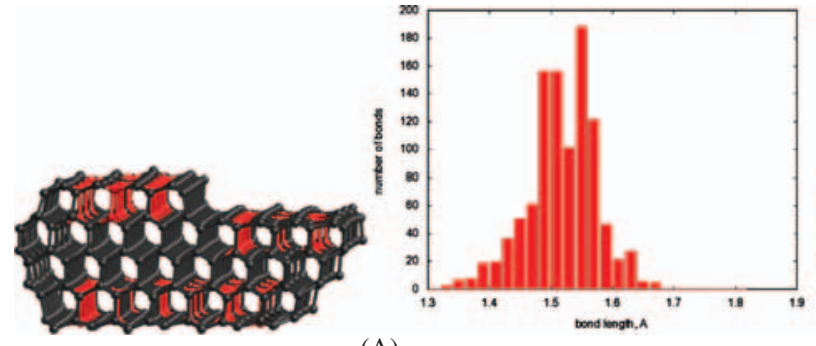

(A)

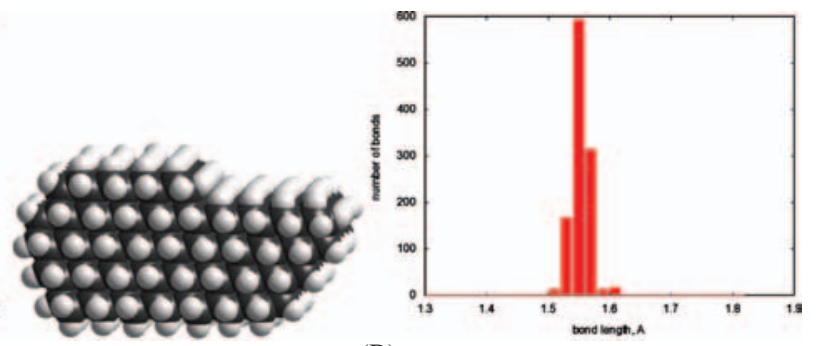

(B)

Fig. 10. Convex and concave $\mathrm{C}(111)-\mathrm{C}(111)$ edgelines: (a) clean and (b) hydrogenated Step111B showing convex (top of step) and concave (bottom of step) $\mathrm{C}(111)-\mathrm{C}(111)$ edgelines $(\mathrm{C}=$ black, $\mathrm{H}=$ white). $\mathrm{C} C$ bondlengths $\geq 1.70 \AA$ in red; bondlength histograms to right of each structure.

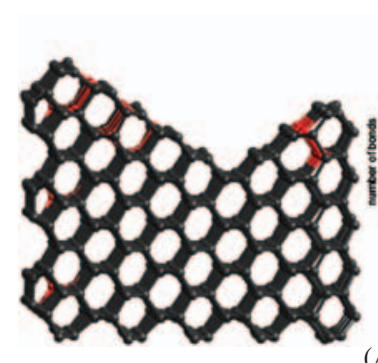

(A)

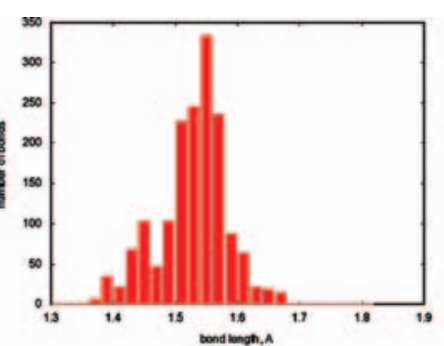

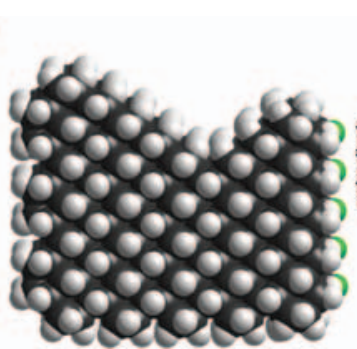

w

B)

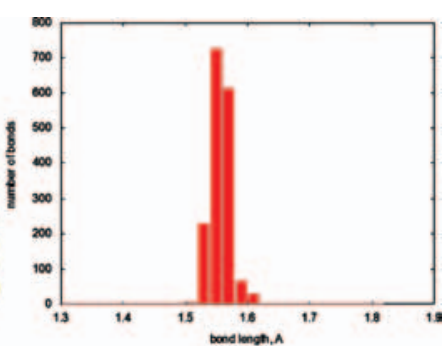

Fig. 11. Concave obtuse-angle $\mathrm{C}(111)-\mathrm{C}(111)$ edgelines: (a) clean and (b) hydrogenated Ledge111-111 $(\mathrm{C}=\mathrm{black}, \mathrm{H}=$ white); $\mathrm{CC}$ bondlengths $\geq 1.70 \AA$ in red; $\mathrm{H}$ atoms (green) are raised $0.1-0.2 \AA$ above the lattice plane; bondlength histograms to right of each structure. 
were done using BLYP (Becke, Lee, Yang, Parr) and PBE (Perdew, Burke, Ernzerhof) ${ }^{20}$ functionals within the generalized-gradient approximation (GGA) and ultrasoft, gradient-corrected, Vanderbilt-type pseudopotentials with a kinetic energy plane-wave cutoff of $340 \mathrm{eV}$ using a cubic periodic supercell in which at least $4 \AA$ of clearance was left between any atom and the periodic cell boundary, giving $>8 \AA$ separation between periodic images. (The more common B3LYP is a hybrid functional containing a Hartree-Fock exchange component, impractical for molecules with extremely large atom counts.) It was often necessary to temporarily relax convergence criteria to obtain the initial wavefunction before returning to normal convergence settings after several optimization steps.

\section{RESULTS AND DISCUSSION}

Geometry optimizations of the nanodiamond structures described in Section 2 yield the results below. For each structure, the clean (dehydrogenated) and hydrogenated variants are shown, with bondlengths $\geq 1.70 \AA$ indicated in red. Each structure is accompanied by a histogram showing the number of bonds as a function of bondlength in the 1.3-1.9 $\AA$ range for all $\mathrm{CC}$ bonds in each structure.

C100Cube15x15 (Fig. 1a). This is a dehydrogenated diamond cube with $\mathrm{C}(110)$ on the top/bottom and left/right faces and $\mathrm{C}(100)$ on the front/back faces, with an edge cut running parallel to a $\mathrm{C}(110) / \mathrm{C}(110)$ edge, yielding an oblique $\mathrm{C}(100)$ cutface. The bondlength distribution shows a wide spread from 1.34-1.67 $\AA$, indicating some incipient graphitization. The $\mathrm{CC}$ bonds on the topmost surface of the oblique $C(100)$ cutface are $1.38-1.40 \AA$ in length, the same as a typical $\mathrm{C}(100)$ surface, but the uppermost $\mathrm{CC}$ bonds along the periphery of the cutface range from 1.41-1.46 A. Unpaired C atoms along the periphery of the cutface show still higher bond order with bondlengths at 1.24-1.38 $\AA$. Three CC bonds are stretched to or near the breaking point at $1.738 \AA, 1.796 \AA$ and $1.850 \AA$ along the back cutface $C(100) / C(100)$ edge, slightly elevating three $\mathrm{C}$ atoms (shown in green) above the cutface plane. This back edge should be regarded as potentially unstable. CC bonds are slightly stretched to $1.57-1.61 \AA$ in the first subsurface layer below the oblique cutface but the rest of the bonds appear normal. No voids are evident and the cube exterior walls are flat with surface planes perpendicular to neighbors.

C100Cube15x15-H (Fig. 1b). This is the hydrogenated form of the diamond C100Cube15x15 structure. All stretched $\mathrm{CC}$ bonds on the topmost surface of the oblique $\mathrm{C}(100)$ cutface, including the three pathologicallystretched $\mathrm{CC}$ bonds observed in C100Cube15x15, have relaxed to $1.60-1.63 \AA$ which is comparable to the $1.60 \AA$ found on a typical monohydrogenated $C(100)$ surface. All $\mathrm{CC}$ bonds deeper inside the structure are of normal length near $1.54 \AA$ A. The histogram shows a fairly narrow spread in bondlengths of only $1.50-1.63 \AA$. This structure appears to have at least static stability. No graphitization or voids are evident and the exterior cube walls are flat with surface planes perpendicular to neighbors.

Ledge100-110D (Fig. 2a). This is a dehydrogenated diamond cube with $\mathrm{C}(110)$ on the front/back and left/right faces and $\mathrm{C}(100)$ on the top/bottom faces, with the horizontal $\mathrm{C}(100)$ ledge surface emerging from the upper line of $\mathrm{C}$ atoms comprising part of the $\mathrm{C}(110)$ zipper line along the inside edge, having dimer rows running in the left/right direction. The chart shows that there are perhaps a hundred $\mathrm{CC}$ bonds in this structure that lie within the 1.39$1.47 \AA$ range, indicating the start of $\mathrm{sp}^{2}$ hybridization. A handful of bonds exceed $1.70 \AA$ in length, most residing beneath the upper left or lower right corners and none of them involving the ledge or its vicinity. The line of leftmost ledge dimer carbon atoms lie $2.63 \AA$ and $2.89 \AA$ respectively from the nearest two front-to-back lines of $\mathrm{C}$ atoms in the vertical wall, similar to Ledge100-110C (see below). The ledge body shows a slight bend downward toward lower right.

Ledge100-110D-H (Fig. 2b). This is the hydrogenated form of the diamond Ledge100-110D structure. The neighboring front/back $\mathrm{H}$ rows on the vertical and horizontal faces that meet at the inside edge of the ledge are separated by $\sim 1.76 \AA$, modestly interacting and much closer than the $\sim 2.5 \AA$ that separates $\mathrm{H}$ atoms of adjacent undisturbed dimers in a row on $\mathrm{C}(100)$. The $\mathrm{H}$ atoms terminating the leftmost two dimer lines are slightly laterally compressed from the normal $2.5 \AA$ to $2.4 \AA$, and the $\sim 7^{\circ}$ downward bend of the ledge body toward lower right is evidence of modest body strain in the ledge structure.

Ledge100-110C (Fig. 2c). This is a dehydrogenated diamond cube with $\mathrm{C}(110)$ on the front/back and left/right faces and $\mathrm{C}(100)$ on the top/bottom faces, with the horizontal $\mathrm{C}(100)$ ledge surface emerging from the upper line of $\mathrm{C}$ atoms of the $\mathrm{C}(110)$ zipper line along the inside edge, having dimer rows running in the front/back direction. With the ledge placed in the "high" position relative to the two possible hexagon attachment points on the vertical wall, repulsive strain around the inside edge is modestly elevated and the ledge bends slightly downward at lower right. The line of leftmost ledge dimer carbon atoms lies $2.62 \AA$ from the nearest front-to-back line of $\mathrm{C}$ atoms in the vertical wall, similar to the $\sim 2.5 \AA$ separation between adjacent dimer rows. There are only a few seriously stretched ( $\geq 1.70 \AA$ ) CC bonds which suggests a reasonably stable structure.

Ledge100-110C-H (Fig. 2d). This is the hydrogenated form of the diamond Ledge100-110C structure. The front/back $\mathrm{H}$ row buried in the inside ledge edge and the closest neighboring front/back $\mathrm{H}$ row on the horizontal face are directly opposed and separated by only $\sim 1.52-$ $1.55 \AA$, strongly interacting because they are much closer than the 2.3-2.5 $\AA$ that normally separates $\mathrm{H}$ atoms of 
adjacent undisturbed dimers in a row on $\mathrm{C}(100)$. The cutface-side front/back row of $\mathrm{H}$ atoms are bent away from the ledge edge to $115^{\circ}-116^{\circ}$, well above the undisturbed $109^{\circ}$ tetrahedral angle, with the inside edge $\mathrm{H}$ atoms forced downward to $104^{\circ}-105^{\circ}$; the $\sim 7^{\circ}$ downward bend of the ledge toward lower right is further evidence of body strain.

Ledge100-110B (Fig. 2e). This is a dehydrogenated diamond cube with $\mathrm{C}(110)$ on the front/back and left/right faces and $C(100)$ on the top/bottom faces, with the $C(100)$ ledge surface emerging from the lower line of $\mathrm{C}$ atoms of the $\mathrm{C}(110)$ zipper line along the inside edge, having dimer rows running in the left/right direction. Dimers on the horizontal cutface have CC bondlengths of 1.40-1.42 $\AA$ except for the rightmost dimers at the end of all four rows which have CC bondlengths of 1.48-1.53 $\AA$. The topmost horizontal back bonding line shows slight $\mathrm{CC}$ bond compression to $1.46-1.51 \AA$ with one CC bond at $1.39 \AA$. But there's no obvious major strain in the structure and the number of CC bondlengths $\geq 1.70 \AA$ are few, with no seriously stretched bonds anywhere close to the ledge walls or cutface surfaces.

Ledge100-110B-H (Fig. 2f). This is the hydrogenated form of the diamond Ledge100-110B structure. All CC bondlengths in the ledge structure are normal (1.53$1.58 \AA$ ) with the exception of the dimers atop the horizontal ledge surface which have CC bondlengths in the 1.57-1.62 ^ range, representing only modest stretching. The $\mathrm{H}$ row running front/back along the inside edge of the ledge and the nearest front/back $\mathrm{H}$ row on the horizontal ledge face are separated by $\sim 2.1 \AA$, a bit closer than the $\sim 2.5 \AA$ that separates $\mathrm{H}$ atoms of adjacent lines of $C(100)$ dimers but still only weakly interacting. Ledge strain energy appears minimal.

Ledge100-110A (Fig. 2g). This is a dehydrogenated diamond cube with $\mathrm{C}(110)$ on the front/back and left/right faces and $\mathrm{C}(100)$ on the top/bottom faces, with the $\mathrm{C}(100)$ ledge surface emerging from the lower line of $\mathrm{C}$ atoms of the $\mathrm{C}(110)$ zipper line along the inside edge, having dimer rows running in the front/back direction. With the ledge in the "low" position relative to the vertical wall (the ledge is moved a half-cage downward relative to Ledge100110C in Fig. 2c), repulsive strain around the inside edge is relieved and the ledge shows no appreciable downward bend at lower right. The diagonal $\mathrm{CC}$ bonds between the lower $\mathrm{C}$ atoms along the inside edge $\mathrm{C}(100)$ zipper line and the $\mathrm{C}$ atoms back into the larger body at left and below the edgeline are a bit stretched, at 1.62-1.65 $\AA$, relative to the more normal $1.50-1.57 \AA$ bondlength, and the two rows of bonds above these stretched bonds are a bit compressed (1.49-1.51 $)$ ). But there's no obvious major strain in the structure and the number of $\mathrm{CC}$ bondlengths $\geq 1.70 \AA$ are few. Those few are mostly confined to the tiny section of $\mathrm{C}(111)$ surface at lower right (bondlengths 1.71-1.92 $\AA$ ) well away from the cutface, and there are only two seriously stretched bonds (1.76 $\AA, 1.79 \AA$ ) in the layer immediately below the ledge cutface along the front.
Ledge100-110A-H (Fig. 2h). This is the hydrogenated form of the diamond Ledge100-110A structure. A few $\mathrm{CC}$ bondlengths along the edge are slightly stretched over a 1.53-1.60 $\AA$ range, but most are in the normal 1.53$1.56 \AA$ range. The small number of highly stretched or broken bonds in the lower right corner of Ledge100-110A are fully healed to $1.54-1.57 \AA$ after hydrogenation. The neighboring front/back $\mathrm{H}$ rows on the vertical and horizontal faces that meet at the inside edge of the ledge are separated by $\sim 1.9 \AA$, slightly larger than the $\sim 1.8 \AA$ that separates $\mathrm{H}$ atoms of adjacent rows on $\mathrm{C}(110)$ and suggesting that the ledge strain energy is minimal.

CutCube15x15 (Fig. 3a). This is a dehydrogenated diamond cube with $\mathrm{C}(110)$ on the top/bottom and front/back faces and $\mathrm{C}(100)$ on the left/right faces, with a corner cut running parallel to a $\mathrm{C}(100) / \mathrm{C}(110)$ edge, yielding an oblique $\mathrm{C}(111)$ cutface; the $\mathrm{C}(100)$ dimer rows on the rightmost vertical face run front/back. The $\mathrm{CC}$ bondlengths $\geq 1.70 \AA$ are mostly confined to interplane bonds below the top layer of the unpassivated diamond $C(111)$ surface on the oblique cutface at upper right, and similarly below two small sections of unpassivated $\mathrm{C}(111)$ in the upper left and lower right corner, indicating incipient graphitization. The two $\mathrm{C}(100) / \mathrm{C}(110) / \mathrm{C}(111)$ convex "triple corners" (corner atoms on front face and back face marked in green) exhibit no obvious structural or bonding anomalies.

CutCube15x15-H (Fig. 3b). This is the hydrogenated form of the diamond CutCube $15 \times 15$ structure. The CC bondlengths are a very normal 1.53-1.57 $\AA$ within the topmost plane of the $\mathrm{C}(111)$ surface on the oblique cutface. The periphery of the cutface along one $\mathrm{C}(111) / \mathrm{C}(110)$ edge has four slightly stretched or higher-order bonds (1.610 $\AA$ and $1.419 \AA, 1.477 \AA, 1.495 \AA$, respectively) but this produces only $\sim 0.1 \AA$ dislocation in the nanodiamond geometric shape near one corner of the cutface. The CC bondlengths are 1.51-1.58 $\AA$ for the topmost interplane bonds and $1.50-1.57 \AA$ in the second plane, giving no evidence of graphitization.

CutCube15x15A (Fig. 3c). This is a dehydrogenated diamond cube with $\mathrm{C}(110)$ on the top/bottom and front/back faces and $\mathrm{C}(100)$ on the left/right faces, with a corner cut running parallel to a $C(100) / C(110)$ edge, yielding an oblique $C(111)$ cutface; the $C(100)$ dimer rows on the rightmost vertical face run top/bottom. The $\mathrm{CC}$ bondlengths $\geq 1.70 \AA$ are confined to a few interplane bonds below the top layer of the unpassivated diamond $\mathrm{C}(111)$ surface on the oblique cutface at upper right, and similarly below a small section of unpassivated C(111) in the upper left corner, indicating incipient graphitization. The two $\mathrm{C}(100) / \mathrm{C}(110) / \mathrm{C}(111)$ convex "triple corners" (corner atoms on front face and back face marked in green) exhibit no obvious structural or bonding anomalies.

CutCube15x15A-H (Fig. 3d). This is the hydrogenated form of the diamond CutCube $15 \times 15 \mathrm{~A}$ structure. The CC bondlengths are a very normal $1.53-1.57 \AA$ within the topmost plane of the $\mathrm{C}(111)$ surface on the oblique cutface. 
Other CC bondlengths are essentially normal and give no evidence of graphitization.

Step111AA (Fig. 4a). This is a rectangular segment of a dehydrogenated diamond cube with $\mathrm{C}(110)$ on the front/back faces, dimerized $\mathrm{C}(100)$ on the left face, $\mathrm{C}(111)$ on the top/bottom and right faces, and a dimerized $\mathrm{C}(100)$ edge at upper right running front/back, with a single-cage $C(100)$ vertical step face having a pre-selected dimerization pattern running front/back on the top surface of the structure. This shows that pre-selecting the lower-energy 2-2-2-1 dimerization pattern yields a more stable predicted structure (compare Step111A below) with no onionization or internal void openings, although incipient graphitization of the $\mathrm{C}(111)$ surfaces is still observed with stretched CC bondlengths $\geq 1.70 \AA$ seen only under those surfaces.

Step111AA-H (Fig. 4b). This is the hydrogenated form of the diamond Step111AA structure. This structure looks very stable.

Step111A (Fig. 4c). This is a rectangular segment of a flattened dehydrogenated diamond cube with $\mathrm{C}(110)$ on the front/back faces, dimerized $\mathrm{C}(100)$ on the left face, $\mathrm{C}(111)$ on the top/bottom and right faces, and a dimerized $\mathrm{C}(100)$ edge at upper right running front/back, with a single-cage $\mathrm{C}(100)$ vertical step face having no preselected dimerization pattern running front/back on the top surface of the structure. After geometry optimization, the step face had dimerized in a higher-energy 2-2-1-2 pattern (compared to Step111AA above), inducing serious graphitization and causing many internal voids to open up as the surface layer separates from the second layer immediately below it. The bottom surface of the nanopart has completely onionized into a curved surface, whose outer layer is riddled with 3-, 5-, 8-, 9-, 10-, 11- and 15-member rings. The in-plane $\mathrm{CC}$ bondlengths on the plateau below the step and on the rounded bottom surface lie in the 1.41-1.47 range, indicating graphene formation; the $\mathrm{CC}$ bonds on the plateau above the step are a bit longer, so here the conversion from $\mathrm{sp}^{3}$ to $\mathrm{sp}^{2}$ is not quite complete. At the step itself, vertical CC bondlengths are in the 1.510-1.537 $\AA$ range except for one bond at $1.466 \AA$, indicating persistent $\mathrm{sp}^{3}$ character; horizontal $\mathrm{CC}$ bondlengths are also in the 1.509-1.579 $\AA$ range except for one likely $\mathrm{C}=\mathrm{C}$ double bond $(1.298 \AA)$ at the far edge. The variance with Step111AA results suggests that these structures may have energy barriers to graphitization that can be surmounted by thermal energy, in which case MD simulation may be a better way to find minimum than conventional (e.g., conjugate gradient) minimization. It seems reasonable to expect that in cases exhibiting the onset of graphitization, this process is likely to proceed further.

Ledge100-111A (Fig. 5a). This is a dehydrogenated diamond cube with $\mathrm{C}(110)$ on the front/back and left/right faces and $\mathrm{C}(100)$ on the top/bottom faces, featuring a horizontal cutface with an obtuse $\left(>90^{\circ}\right)$ concave ledge angle with the $C(100)$ ledge surface having dimer rows running left/right. The cutface $\mathrm{CC}$ bondlengths on the oblique cutface above the concave edgeline lie in the normal 1.50$1.54 \AA$ range. The $\mathrm{CC}$ bondlengths on the horizontal cutface to the right of and nearest to the concave edgeline are a bit shorter (1.47-1.52 $\AA$ ), with a few still shorter bonds further from the edgeline. The histogram indicates several hundred CC bondlengths in the 1.39-1.47 $\AA$ ( $\mathrm{sp}^{2}$ bonding) range. There are a few stretched interlayer bonds in the 1.60-1.81 $\AA$ range. This indicates that at least a few interlayer bonds have broken and some graphitization has begun on the $\mathrm{C}(111)$ side of the ledge, but not on the $\mathrm{C}(100)$ side which seems to have retained $\mathrm{sp}^{3}$ bonding.

Ledge100-111A-H (Fig. 5b). This is the hydrogenated form of the diamond Ledge100-111A structure. CC bonds are in the near-normal 1.55-1.58 $\AA$ range along the inside edge. The front/back row of $\mathrm{H}$ atoms just below the concave edgeline bends slightly to $113^{\circ}$, about $4^{\circ}$ from normal tetrahedral, but the similar row of $\mathrm{H}$ atoms just above the edgeline shows no angular distortion. These upper and lower front/back $\mathrm{H}$ rows are separated by $\sim 2.5 \AA$, exceeding the $\sim 2.2-2.4 \AA$ that separates $\mathrm{H}$ atoms in adjacent rows of $\mathrm{C}(100)$ dimers and confirming that ledge body strain should be modest in this very stable structure.

Ledge100-111B (Fig. 5c). This is a dehydrogenated diamond cube with $\mathrm{C}(110)$ on the front/back and left/right faces and $\mathrm{C}(100)$ on the top/bottom faces, featuring a horizontal cutface with an obtuse $\left(>90^{\circ}\right)$ concave ledge angle with the $\mathrm{C}(100)$ ledge surface having dimer rows running front/back. As with the Ledge100-111A structure, the two $\mathrm{C}(111)$ surfaces shown incipient graphitization. Here again there are several hundred $\mathrm{CC}$ bondlengths in the 1.37$1.47 \AA$ range indicating the formation of $\mathrm{sp}^{2}$ bonding, while the $\mathrm{C}(100)$ side of the ledge seems to have retained $\mathrm{sp}^{3}$ bonding.

Ledge100-111B-H (Fig. 5d). This is the hydrogenated form of the diamond Ledge100-111B structure. CC bonds are slightly stretched in the $1.57-1.60 \AA$ range along the inside edge. The front/back row of $\mathrm{H}$ atoms below the concave edgeline bends modestly to $114^{\circ} \mathrm{deg}$, about $5^{\circ}$ degrees from normal tetrahedral, but the upper row of $\mathrm{H}$ atoms shows no angular distortion. The upper and lower front/back $H$ rows are separated by $\sim 1.9 \AA$, a bit closer than the $\sim 2.2-2.4 \AA$ that separates $\mathrm{H}$ atoms in adjacent rows of $C(100)$ dimers but still consistent with only modest strain in the ledge body.

Ledge100-111D (Fig. 6a). This is a dehydrogenated diamond cube with $\mathrm{C}(110)$ on the front/back and left/right faces and $\mathrm{C}(100)$ on the top/bottom faces, featuring a horizontal cutface with an acute $\left(<90^{\circ}\right)$ concave ledge angle with the $C(100)$ ledge surface having dimer rows running left/right. The oblique $\mathrm{C}(111)$ surface above the edgeline has only one section of overstretched interlayer bonds, compared to two for Ledge100-111A (Fig. 5a) and three for Ledge100-111B (Fig. 5c), so this pure nanocarbon structure appears somewhat more stable than $\mathrm{A}$ or B. A small section of $\mathrm{C}(111)$ at upper right, just below 
the horizontal cutface, shows graphitization, and the structure includes several hundred $\mathrm{CC}$ bondlengths in the 1.35$1.47 \AA$ range, indicating the formation of $\mathrm{sp}^{2}$ bonding with incipient graphitization.

Ledge100-111D-H (Fig. 6b). This is the hydrogenated form of the diamond Ledge100-111D structure. While most $\mathrm{CC}$ bondlengths near the inside edgeline are in the 1.56-1.59 $\AA$ range, a few $\mathrm{CC}$ bonds along edgeline are moderately stretched (1.62-1.65 $\AA$ ). The neighboring $\mathrm{H}$ rows on the vertical and horizontal faces that meet at the inside edge of the ledge are separated by $\sim 1.7 \AA$, much closer than the $\sim 2.5 \AA$ that separates $\mathrm{H}$ atoms of adjacent undisturbed dimers along a line on $\mathrm{C}(100)$. The $\mathrm{H}$ bond angles are asymmetric by about $6 \mathrm{deg}\left(107^{\circ}\right.$ versus $113^{\circ}$ along the $\mathrm{C}(111)$ edge, $111^{\circ}$ versus $105^{\circ}$ along the $\mathrm{C}(110)$ edge) and the $\mathrm{H}$ atoms terminating the leftmost two dimer lines are slightly compressed from the normal $2.5 \AA$ to $2.4 \AA$. The upper ledge body is tilted slightly upward to the right and the $\sim 7^{\circ}$ downward bend of the ledge toward lower right is further evidence of modest repulsive strain on either side of the concave edgeline.

Ledge100-111C (Fig. 6c). This is a dehydrogenated diamond cube with $\mathrm{C}(110)$ on the front/back and left/right faces and $\mathrm{C}(100)$ on the top/bottom faces, featuring a horizontal cutface with an acute $\left(<90^{\circ}\right)$ concave ledge angle with the $C(100)$ ledge surface having dimer rows running front/back. The resulting structure shows a graphitization and bonding pattern similar to Ledge100-111D (Fig. 6a).

Ledge100-111C-H (Fig. 6d). This is the hydrogenated form of the diamond Ledge100-111C structure. The $\mathrm{C}(111)$ surface is stable and has not begun to graphitize: CC bondlengths in the top surface range from 1.53-1.57 $\AA$, which is normal for diamond lattice. The surface-subsurface interlayer bonds are in the ranges of 1.57-1.60 A (inside edge cell), 1.52-1.54 ̊ (second cell, moving right), $1.54-1.57 \AA$ (third cell), and 1.53-1.55 (fourth cell), normal for $\mathrm{sp}^{3}$ bonding. A major issue for this structure is the acute angle between the oblique (upper) and horizontal ledge faces, which forces one line of passivating $\mathrm{H}$ atoms on the upper ledge face into close proximity with two rows of passivating $\mathrm{H}$ atoms on the lower ledge face, causing physical distortion of the ledge structure. In particular, the proximity of the lowest $\mathrm{H}$ atom row on the oblique face to the leftmost $\mathrm{H}$ atom row on the horizontal face ranges from 1.47-1.52 $\AA$, and the distances to the next $\mathrm{H}$ atom row up the oblique face range from 2.08-2.22 $\AA$, both of which are significantly smaller than the $\sim 2.5 \AA$ separation between $\mathrm{H}$ atoms of adjacent undisturbed dimers along a line on $\mathrm{C}(100)$. The leftmost row of $\mathrm{H}$ atoms running front/back on the horizontal ledge face bends to the right giving a $\mathrm{C}-\mathrm{C}-\mathrm{H}$ angle of $116^{\circ}$, or $7^{\circ}$ above the normal $109^{\circ}$ tetrahedral angle. The next highest $\mathrm{H}$ atom row on the oblique face is undisturbed at $109^{\circ}$, in part because these $\mathrm{H}$ atoms lie midway between the nearest horizontal face $\mathrm{H}$ atoms, but the lowest $\mathrm{H}$ atom row on the oblique face is bent downward to $104^{\circ}$, or $5^{\circ}$ above the normal $109^{\circ}$ tetrahedral angle. The downward bend of the ledge toward lower right along with the upward bend of the top section away from the ledge at upper left is further evidence of significant body strain in this ledge structure.

Ledge100-111E (Fig. 6e). This is a dehydrogenated diamond cube with $\mathrm{C}(110)$ on the front/back and left/right faces and $\mathrm{C}(100)$ on the top/bottom faces, featuring a horizontal cutface with an acute $\left(<90^{\circ}\right)$ concave ledge angle with the $\mathrm{C}(100)$ ledge surface having dimer rows running front/back, but with the horizontal cleavage plane positioned half a cage lower down the oblique wall relative than the cutplane in Ledge100-111C (Fig. 6c). This appears to alleviate most of the strain in the structure. The C(111) surfaces show only weak signs of incipient graphitization with only a handful of $\mathrm{CC}$ bondlengths exceeding $1.70 \AA$. There are several hundred CC bondlengths in the 1.37-1.47 $\AA$ range and quite a few $\sim 1.49 \AA \mathrm{CC}$ bonds in the top surface but the surface-subsurface interlayer bonds are in the ranges of 1.55-1.58 $\AA$ (inside edge cell), 1.61$1.68 \AA$ (second cell, moving right), and 1.63-1.70 $\AA$ (third cell), so no bonds have likely broken yet.

Ledge100-111E-H (Fig. 6f). This is the hydrogenated form of the diamond Ledge100-111E structure. The longest CC bondlengths are all in the 1.56-1.59 $\AA$ range, indicating no bond strain of any significance. The whole structure looks very undistorted, including the apposed $\mathrm{H}$ rows on either side of the edgeline which appear positionally undistorted.

Ledge110-110 (Fig. 7a). This is a dehydrogenated diamond cube with $\mathrm{C}(110)$ on the left/right and top/bottom faces and $\mathrm{C}(100)$ on the front/back faces, featuring two orthogonal $\mathrm{C}(110)$ cutfaces making a right angle $\left(90^{\circ}\right)$ ledge on the top face. The $\mathrm{C}(110)$ vertical and horizontal ledge faces look flat and undisturbed. Surface CC bondlengths on the horizontal cutface are 1.42-1.53 $\AA$ and 1.49-1.52 $\AA$ for the interlayer bonds below this surface, and the lack of curvature to the surface indicates no onionization has occurred. The next sublayer and below shows only $\mathrm{sp}^{3}$ bonding. The vertical ledge face and its subsurface layers show similar structure. Unrelated to the ledge, there are eight bondlengths $\geq 1.70 \AA$, all but one probably broken, with four (1.71-1.94 $\AA$ ) along the back left vertical edge and four (1.83-1.94 $\AA$ ) along the front bottom horizontal edge, both involving small strips of $\mathrm{C}(111)$ surface that are beginning to rearrange.

Ledge110-110-H (Fig. 7b). This is the hydrogenated form of the diamond Ledge110-110 structure. The inside edge of this ledge has CC bonds with virtually no strain and the apposed $\mathrm{H}$ rows appear angularly undistorted. There is a very narrow range of bondlengths in this structure, with almost all $\mathrm{CC}$ bondlength within 1.49-1.61 $\AA$ and most in the 1.53-1.59 $\AA$ range. This is a very stable and undistorted structure with extremely flat faces.

Ledge110-111 (Fig. 8a). This is a dehydrogenated diamond or "nanocarbon" cube with $\mathrm{C}(110)$ on four faces 
and $\mathrm{C}(100)$ on two faces. The ledge is a near-diagonal cut, leaving a vertical $\mathrm{C}(110)$ wall and a horizontal $\mathrm{C}(111)$ cutface. There are several hundred $\mathrm{CC}$ bondlengths in the 1.35-1.47 $\AA$ range, mostly in perimeter and surface locations, indicating some $\mathrm{sp}^{2}$ bond formation. One small strip of $\mathrm{C}(111)$ along a back upper right diagonal and another small bit of additional C(111) surface running front/back at the bottom corner each has three CC bondlengths $>1.70 \AA$ indicating incipient graphitization.

Unexpectedly, the large horizontal C(111) cutface did not massively reconstruct. In the initial run (Ledge110111), ignoring the outermost perimeter bonds almost all interlayer $\mathrm{CC}$ bondlengths between the top cutface surface and its subsurface were 1.58-1.64 $\AA$ (indicating moderate bond strain but no bond breakage), with in-plane CC bonds within the cutface surface at 1.49-1.57 $\AA$ (normal for diamond lattice) and no high-strain $\geq 1.70 \AA$ interlayer bonds. After a short MD run and reoptimization of the same structure, about half of the vertical $\mathrm{CC}$ bondlengths under the top layer increased to $1.64-1.67 \AA$, still not quite broken but evidencing some additional stretch (i.e., incipient graphitization) and raising the possibility that we are still looking at an intermediate or metastable structure.

Another potential explanation for the lack of massive reconstruction is that the presence of a vertical wall with the $C(110)$ surface might augment lattice stability by providing structural rigidity beyond mere surface passivation stabilization (which by itself would be insufficient to prevent reconstruction of such a large section of bare $C(111)$ surface $\left.^{1}\right)$. To investigate this, the entire vertical wall was removed and a geometry optimization was performed on the remaining flat-top structure (Ledge110111B) (Fig. 8c). After optimization, the top interlayer vertical CC bondlengths lie mostly in the 1.64-1.69 range but a number of high-strain $\geq 1.70 \AA \mathrm{CC}$ bonds have appeared. Given that the spread of bondlengths seems somewhat narrower for Ledge110-111A than for Ledge110-111B, the presence of a C(110) face on the vertical wall of a concave ledge might slightly inhibit the progress of reconstruction on an adjacent horizontal clean $C(111)$ surface, a possibility that should be investigated in future work. In contrast, note that dehydrogenated Step111AA (Fig. 4a) with a one-cage-high C(100) vertical wall and dehydrogenated Step111B (Fig. 10a) with a onecage-high $\mathrm{C}(111)$ vertical wall do not prevent the adjacent clean $\mathrm{C}(111)$ surface from initiating reconstruction.

Ledge110-111-H (Fig. 8b). This is the hydrogenated form of the diamond Ledge110-111 structure. The structure possesses almost exclusively low-strain CC bondlengths between 1.51-1.61 $\AA$. The adjacent lines of $\mathrm{H}$ atoms running front/back along the concave ledge edge are separated by $1.4 \AA$, much closer than the $2.55 \AA$ separation between passivating $\mathrm{H}$ atoms on an open $\mathrm{C}(111)-\mathrm{H}(1 \mathrm{x} 1)$ surface, and yet the overall geometry of the nanodiamond shows almost no distortion possibly due to the thickness of the ledge shelf. The $\mathrm{C}-\mathrm{C}-\mathrm{H}$ bond angles on the inside ledge edge are $111^{\circ}$ on the horizontal side and $108^{\circ}-111^{\circ}$ on the vertical side, not far from the $109^{\circ}$ tetrahedral angle, perhaps because the $\mathrm{H}$ atoms on the horizontal side are spaced very widely apart $(\sim 4.4 \AA)$.

Octa16x16 (Fig. 9a). This is the dehydrogenated form of an hydrocarbon octahedron the next size larger than Octa14x14 in the previous paper, ${ }^{1}$ with $\mathrm{C}(111)$ surfaces on all eight faces of the object which has a $20.0 \AA$ edge and a $28.3 \AA$ diagonal with a total of 969 atoms. This is a good example of a 4-plane convex corner. Octa16x16 differs from the smaller octahedrons in that it is not completely onionized. In contrast with Octa14x14 (Fig. 9c), the outer shell is not separated and overall structure seems to be diamond, not fullerenic. Two runs with different optimization options gave similar results - either such a large structure makes the optimizer more prone to fall into a local minimum, or the $16 \times 16$ octahedron actually possesses more structural stability. The partially separated $\mathrm{sp}^{3}$ core is shown in green. Note also that the CC bondlengths $\geq 1.70 \AA$ lie exclusively around the outermost layer, separating that layer from the inner pure diamond core. This structure lies near the transitional size between the fullerenic and nanodiamond regimes where the diamond phase is thermodynamically the most stable form for pure carbon nanoparticles. ${ }^{1}$

Octa16x16-H (Fig. 9b). This is the hydrogenated version of Octa16x16, a structure with a $22.2 \AA$ edge and a $30.1 \AA$ diagonal and a total of 1293 atoms. Note that while these may not be the lowest energy structures in the dehydrogenated cases-e.g., the carbene corners could invert into the clean structure, possibly forming a lower energy structure-for the hydrogenated structures these are much more likely to be the lowest energy structures because of the uniformity of bond angles and bondlengths, and because all valences are satisfied via simple regular tetrahedral coordination.

Step111B (Fig. 10a). This is a rectangular segment of a dehydrogenated diamond cube with $\mathrm{C}(110)$ on the front/back faces, dimerized $\mathrm{C}(100)$ on the right face, $\mathrm{C}(111)$ on the top/bottom and left faces, and a dimerized $C(100)$ edge at upper left running front/back, with a single-cage $\mathrm{C}(111)$ vertical step face which is obtained by starting the step from the other side of the cube than in Step111AA (Fig. 4a). As in Step111AA, no onionization or major internal voids have opened although graphitization of all $\mathrm{C}(111)$ surfaces occurs with large numbers of interlayer CC bonds $\geq 1.70 \AA$.

Step111B-H (Fig. 10b). This is the hydrogenated form of the diamond Step111B structure, a step structure with the $\mathrm{C}(100)$ face reconstructed into dimers, then passivated with $1 \mathrm{H}$ monolayer. All surface and nearby interior $\mathrm{CC}$ bondlengths lie in the normal 1.53-1.57 $\AA$ range. Along the front/back concave step edge, the two rows of opposed $\mathrm{H}$ atoms have interatomic separations in the 2.08-2.15 
range, almost double the normal $1.09 \AA \mathrm{C}-\mathrm{H}$ bondlength and far enough apart so that very little $\mathrm{H}-\mathrm{H}$ interaction is expected, as confirmed by $\mathrm{C}-\mathrm{C}-\mathrm{H}$ bond angles tightly clustered in the $109^{\circ}-111^{\circ}$ range for both rows, indicating virtually no deviation from ideal tetrahedral symmetry. Dimer formation on the $\mathrm{C}(100)$ faces pulls the next layer slightly out of perfectly regular spacing, corresponding to the new dimer positions, but by the second layer this slight lattice irregularity has almost completely disappeared.
Ledge111-111 (Fig. 11a). This is a dehydrogenated diamond cube with $\mathrm{C}(110)$ on the front/back and top/bottom faces and $\mathrm{C}(100)$ on the left/right faces, featuring two oblique $\mathrm{C}(111)$ cutfaces with an obtuse $\left(109^{\circ}\right)$ concave ledge angle on the top face. Incipient graphitization is visible on both $\mathrm{C}(111)$ cutfaces, with stressed bonds $\geq 1.70 \AA$ appearing in three rows of interlayer bonds (up to $1.73 \AA$ ) under the left cutface surface and in one row of interlayer bonds (up to $1.76 \AA$ ) under the right cutface surface,
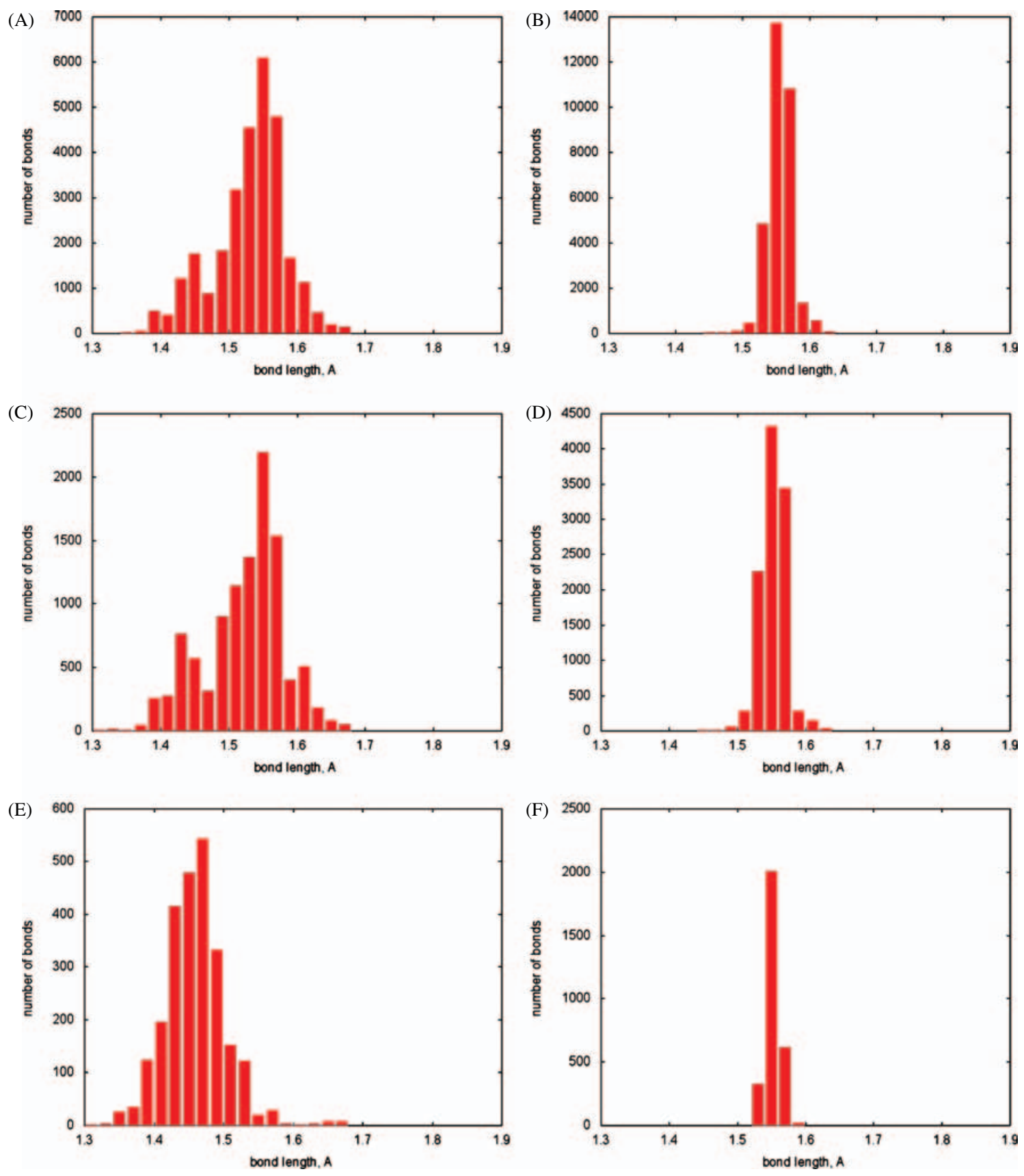

Fig. 12. Cumulative bondlength histograms are provided for all (a) clean and (b) hydrogenated ledge and step structures described in this paper, and additionally for all (c) clean and (d) hydrogenated cuboid structures and for all (e) clean and (f) hydrogenated octahedron structures reported in previous work. ${ }^{1}$ 
and many other interlayer bonds in the 1.60-1.70 ̊ range immediately beneath these two cutfaces. Future molecular dynamics studies might ascertain whether graphitization preferentially initiates at concave $\mathrm{C}(111) / \mathrm{C}(111)$ edges as it is thought to do at convex edges. ${ }^{21}$ On the left back edge running top/bottom there is a third small $\mathrm{C}(111)$ face that is not a part of the ledge structure, immediately beneath which there are three 1.83-1.91 $\AA$ interlayer bonds that appear broken, suggesting that internal void formation has begun. Throughout the structure there are also several hundred CC bondlengths in the 1.35-1.47 $\AA$ range that may indicate $\mathrm{sp}^{2}$ rehybridization.

Ledge111-111-H (Fig. 11b). This is the hydrogenated form of the diamond Ledge111-111 structure. It is a ledge structure defined by the joining of two C(111) surfaces along a common edgeline. The structure looks clean, regular, unstrained and undistorted. The surface $\mathrm{CC}$ bonds are all in the 1.53-1.58 $\AA$ range, indicating pure $\mathrm{sp}^{3}$ bonding. Along the edgeline where the two cutfaces meet, the two rows of closest opposed $\mathrm{H}$ atoms have interatomic separations in the 2.0-2.1 $\AA$ range, much less than the normal $2.5 \AA$ separation between $\mathrm{H}$ atoms on passivated $\mathrm{C}(111)$ but still far enough apart so that very little $\mathrm{H}-\mathrm{H}$ interaction is expected, as confirmed by the associated $\mathrm{C}-\mathrm{C}-\mathrm{H}$ bond angles which remain tightly clustered in the $109^{\circ}-$ $111^{\circ}$ range for both rows, indicating virtually no deviation from ideal tetrahedral symmetry. The $\mathrm{C}(111)$ corner at back left with the three broken bonds in Ledge111-111 is repaired, with all CC bondlengths now in the 1.52-1.59 $\AA$ range.

Hydrogenated versus Dehydrogenated Ledge and Step Structures. A cumulative comparison of bondlength distributions for all clean (Fig. 12a) and hydrogenated (Fig. 12b) ledge and step structures described in this paper shows the expected narrower distribution for the hydrogenated forms, well-clustered around the $\mathrm{sp}^{3} \mathrm{CC}$ bondlength of $1.54 \AA$. The dehydrogenated forms reveal many stretched bonds and altered bond-orders with bondlengths peaking in the 1.42-1.45 $\AA$ range, indicating $\mathrm{sp}^{2}$ bond formation and incipient or actual graphitization. Similar results are obtained for all clean (Fig. 12c) and hydrogenated (Fig. 12d) cuboid structures and for all clean (Fig. 12e) and hydrogenated (Fig. 12f) octahedron structures that were reported in previous work. ${ }^{1}$ An analysis of the consequences of isolated $\mathrm{H}$ atom removals (both singly and in multi-H patterns) from the three principal diamond surfaces and the robustness of these slightly dehydrogenated diamond surfaces near several convex edges was reported in previous work. ${ }^{1}$

\section{CONCLUSIONS}

Computational studies using Density Functional Theory (DFT) confirm that fully hydrogenated nanodiamonds $1-2 \mathrm{~nm}$ in size ( 900-1700 atoms) possessing ledge features with various combinations of convex or concave edgelines joining any two of the three principal diamond faces will maintain stable $\mathrm{sp}^{3}$ hybridization. This result applies to nanodiamonds with concave ledges that have acute, normal, or obtuse angles or that have step walls that are one or more adamantane cages in height. Convex edgelines seem generally stable, as are concave edgelines formed from the intersection of $\mathrm{C}(110)-\mathrm{C}(110), \mathrm{C}(110)$ $\mathrm{C}(111)$ and $\mathrm{C}(111)-\mathrm{C}(111)$ surfaces.

Concave edgelines formed from the intersection of $\mathrm{C}(100)-\mathrm{C}(110)$ or $\mathrm{C}(100)-\mathrm{C}(111)$ surfaces can have two possible configurations. When the edgeline of the concave ledge is positioned in the "high" position relative to the two possible hexagon attachment points on the vertical wall, moderate strain appears in the ledge body which can cause gross geometric distortions in the $5^{\circ}-10^{\circ}$ range. When the edgeline of the concave ledge is positioned in the "low" position relative to the vertical wall, repulsive strain around the inside edge is relieved and the ledge body shows no appreciable geometric distortion.

The possibility that the presence of a vertical C(110) ledge wall might slightly hinder reconstruction of an adjacent clean $C(111)$ surface should be investigated further.

Bondlength distributions for clean and hydrogenated step structures described in this paper show the expected narrower distribution for the hydrogenated forms, wellclustered around the $\mathrm{sp}^{3} \mathrm{CC}$ bondlength of $1.54 \AA$. The dehydrogenated forms reveal many stretched bonds and altered bond-orders with bondlengths peaking in the 1.42$1.45 \AA$ range, indicating $\mathrm{sp}^{2}$ bond formation and incipient or actual graphitization.

We conclude that H-passivated diamond nanoparts having certain simple features including ledges, steps, and corners possess at least static structural stability. These results support the viability of proposals to use such nanoparts as components of nanoscale diamondoid nanomachines and nanomachine systems.

\section{References}

1. D. Tarasov, E. Izotova, D. Alisheva, N. Akberova, and R. A. Freitas, Jr., J. Comput. Theor. Nanosci. 8, 147 (2011).

2. R. A. Freitas, Jr. and R. C. Merkle, J. Comput. Theor. Nanosci. 5, 760 (2008)

3. D. Tarasov, N. Akberova, E. Izotova, D. Alisheva, M. Astafiev, and R. A. Freitas, Jr., J. Comput. Theor. Nanosci. 7, 325 (2010).

4. N. Oyabu, O. Custance, I. Yi, Y. Sugawara, and S. Morita, Phys. Rev. Lett. 90, 176102 (2003).

5. N. Oyabu, O. Custance, M. Abe, and S. Moritabe, Abstracts of Seventh International Conference on non-contact Atomic Force Microscopy, Seattle, Washington, USA, 12-15 September 2004, (2004), p. 34

6. Y. Sugimoto, P. Pou, O. Custance, P. Jelinek, M. Abe, R. Perez, and S. Morita, Science 322, 413 (2008).

7. P. Moriarty, Digital Matter: Towards Mechanised Mechanosynthesis, EPSRC Fellowship proposal (2008).

8. R. E. Tuzun, D. W. Noid, and B. G. Sumpter, J. Chem. Phys. 105, 5494 (1996).

9. K. Sohlberg, R. E. Tuzun, B. G. Sumpter, and D. W. Noid, Nanotechnology 8, 103 (1997).

J. Comput. Theor. Nanosci. 9, 1-15, 2012 
10. D. W. Noid, R. E. Tuzun, and B. G. Sumpter, Nanotechnology 8, 119 (1997).

11. D. H. Robertson, B. I. Dunlap, D. W. Brenner, J. W. Mintmire, C. T. White, et al., Novel Forms of Carbon II, edited by C. L. Renschler, D. M. Cox, J. J. Pouch, and Y. Achiba, MRS Symposium Proceedings Series 349, 283 (1994).

12. J. Han, A. Globus, R. Jaffe, and G. Deardorff, Nanotechnology 8, 95 (1997).

13. A. Globus, C. W. Bauschlicher, Jr., J. Han, R. L. Jaffe, C. Levit, and D. Srivastava, Nanotechnology 9, 192 (1998).

14. R. E. Tuzun, D. W. Noid, and B. G. Sumpter, Nanotechnology 6, 52 (1995).
15. O. A. Shenderova, D. Areshkin, and D. W. Brenner, Mater. Res. 6, 11 (2003).

16. K. E. Drexler, Nanosystems: Molecular Machinery, Manufacturing, and Computation, John Wiley \& Sons, New York (1992).

17. T. Cagin, A. Jaramillo-Botero, G. Gao, and W. A. Goddard, III, Nanotechnology 9, 143 (1998).

18. G. Leach, Nanotechnology 7, 197 (1996).

19. CPMD (Car-Parrinello Molecular Dynamics), http://www.cpmd.org/, copyright IBM Corp. 1990-2008.

20. J. P. Perdew, K. Burke, and M. Ernzerhof, Phys. Rev. Lett. 77, 3865 (1996).

21. L. Li and X. Zhao, J. Chem Phys. 134, 044711 (2011).

Received: 3 March 2011. Accepted: 26 March 2011. 